\title{
Needle Exchange Programs and Experience of Violence in an Inner City Neighborhood
}

\author{
$* \dagger$ Sandro Galea, *Jennifer Ahern, *†Crystal Fuller, $¥$ Nicholas Freudenberg, and $* \dagger$ David Vlahov \\ *Center for Urban Epidemiologic Studies, New York Academy of Medicine, New York; †Department of Epidemiology, Joseph L. \\ Mailman School of Public Health, Columbia University, New York; and $\ddagger$ Program in Urban Public Health, Hunter College, City \\ University of New York, New York, U.S.A.
}

\begin{abstract}
Objective: To assess the association between proximity to a needle exchange program (NEP) and experience of violence in an inner city neighborhood.

Methods: A cross-sectional survey of residents of Harlem, New York City provided data for this study. We used geocoding to obtain the distance between respondents and the nearest NEP. Respondents reported violence they were aware of or had personally experienced in their neighborhood. Multiple logistic regression analyses assessed the relation between violence and distance from the nearest NEP.

Results: Among 220 respondents, 50.1\% were African American, 39.0\% were Latino, $44.7 \%$ were male, and the mean age was 44.5 years. In separate age-, race-, sex-, and income-adjusted logistic regression models, there was no significant association between (1) reporting a fight and distance from the nearest NEP (odds ratio $[\mathrm{OR}]=1.05, p=.89) ;(2)$ robbery in the neighborhood in the previous 6 months and distance from the nearest NEP (OR $=1.13, p=.71)$; (3) ever having experienced violence and distance from the nearest $\mathrm{NEP}(\mathrm{OR}=0.72, p=.52)$; or $(4)$ ever having been robbed by drug users and distance from the nearest NEP $(\mathrm{OR}=1.05, p=.91)$.

Conclusions: There was no consistent association between living close to NEPs and violence reported by residents of Harlem in this study. This study suggests that NEPs do not adversely affect rates of violence in their vicinity.
\end{abstract}

Key Words: Needle exchange programs-Violence-Inner city neighborhood.

Injection drug use is one of the leading causes of HIV transmission in the United States (1). In New York City, approximately half $(47 \%)$ of total reported AIDS cases are a result of injection drug use (2). Needle exchange programs (NEPs) have been implemented in many U.S. cities as a public health measure to reduce transmission of HIV and other infectious disease (e.g., hepatitis B and C) (3-6). NEPs have been shown to reduce risk-taking behavior among injection drug users (IDUs) (7,8), to reduce discarded syringes in neighborhoods (9), and to

Address correspondence and reprint requests to Sandro Galea, Center for Urban Epidemiologic Studies, New York Academy of Medicine, 1216 Fifth Avenue, Room 556, New York, NY 10029-5293, U.S.A.; e-mail: sgalea@nyam.org

Manuscript received March 6, 2001; accepted July 23, 2001. increase referrals to drug abuse treatment among substance users (10-12).

In spite of these benefits, there remains a Congressional ban on federal funding for NEPs in the United States $(13,14)$. Although a number of expert panels have recommended lifting the Congressional ban (15), legislators continue to express concern that NEPs can result in increased drug use, crime, and violence in their vicinity (16). These concerns have not been borne out by recent studies demonstrating that NEPs are cost-effective $(17,18)$ and that the introduction of NEPs does not increase drug use (19-22) or crime rates in the surrounding neighborhoods (23).

Although research has failed to identify an association between official crime records and NEPs, it is possible that persons who live close to NEPs (and who might thus 
have had regular contact with IDUs) experience more violence than persons who do not live close to NEPs. Small acts of violence might go unreported by residents accustomed to IDUs in their neighborhoods (24). Proximity to NEPs might also negatively affect residents' attitudes toward drug use and drug users, potentially setting the stage for a confrontational environment (25).

We were therefore interested in determining whether residents of an inner city neighborhood who lived close to established NEPs observed more acts of violence, experienced more violence, or felt more threatened by drug users than residents of the same neighborhood who were not living as close to these programs. We also assessed the relation between living close to a NEP, disapproval of drug use, and perceptions of drug users' dangerousness. We studied these associations in East and Central Harlem, which are neighborhoods with a welldocumented high prevalence of substance use (26).

\section{METHODS}

\section{Sample}

This study was part of the Harlem Social Environment Study designed to investigate features of the Harlem social environment associated with the well being of Harlem residents. The target population for our study comprised adults over the age of 18 years living in Harlem, New York City in households with telephones during the year 2000. We defined Harlem as the communities of East and Central Harlem in the borough of Manhattan.

We used random-digit-dialing (27) to identify and interview 225 people by telephone who met these criteria and agreed to participate in this study. Five of the individuals surveyed provided insufficient information for address geocoding and were excluded from these analyses. Telephone exchanges with at least $60 \%$ of addresses in East and Central Harlem were identified. Random generation of numbers within those exchanges was then used to reach households. Calls to households were made during evenings, weekends, and normal working hours. Numbers where no one was contacted were called again daily up to 10 days. Once a household was reached, geographic eligibility was determined by asking respondents to identify the major intersection closest to their house. Households close to an intersection within Harlem were considered eligible. For households with more than one adult over the age of 18 years, an eligible respondent was randomly selected using a variation of the Kish procedure (28). We asked to interview the household member whose birth date was closest to the date of our call. This method ensured that a respondent selected was not simply the one who happened to be at home the most or who was most interested in talking on the telephone. We also weighted all responses to account for potential overrepresentation of some individuals in the study. Individuals within households with more than one telephone number had a higher probability of being selected at random. We thus assigned a weight to all respondents inverse to the probability of selection. All analyses were carried out using the weighted sample. This study could detect a minimum odds ratio (OR) of 1.5 between respondents' reports of violence, with $80 \%$ power and $\alpha=0.05$, assuming two groups (respondents living near to or far from NEPs) of equal size.
The study was reviewed and approved by the Institutional Review Board of the New York Academy of Medicine.

\section{Instrument}

The standardized interview included questions regarding each respondent's age, sex, and educational level. Respondents were also asked about their perceptions of drug users, approval or disapproval of drug use, and fear of drug users. We asked if there had been a fight in which a weapon was used or a robbery in their neighborhood in the past 6 months. We also asked respondents if they had ever personally experienced violence or if they had ever been hurt or robbed by drug users in their neighborhood. We pilot-tested all questions by means of telephone and in-person interviews before the start of the study. Telephone interviews averaged 25 minutes in length. The instrument was available in English and Spanish. Back-translation of the instrument from Spanish to English verified consistency of questions asked. Native Spanishand English-speaking interviewers carried out the interviews in their respective languages.

\section{Measures}

\section{Sociodemographic Measures}

Age, race, sex, and all other sociodemographic measures were selfreported. The closest intersection to a respondent's residence was used to ascertain that individuals surveyed lived in Harlem. Age was coded as a categoric variable (i.e., 18-34 years, 35-49 years, 60-64 years, 65 years or older) throughout the analyses. Race was defined according to the three most common groups (African American, Latino, other) and dummy coded. Income was used as a continuous variable. We also determined respondents' personal experiences with drugs by asking if they had ever smoked cigarettes, used alcohol, smoked marijuana, or used cocaine. These responses were coded as dichotomous variables.

\section{Needle Exchange Programs and Distance from Nearest Needle Exchange Program}

We asked all respondents for the closest major intersection to their current place of residence and geocoded all responses. We also geocoded the six current major NEPs in Harlem. All the NEPs considered in this analysis are legally operated New York State-authorized syringe exchange operations. All NEPs have been operating in their locations for several years and are well known to the IDU community. Although the NEPs included in this analysis differ in their syringe exchange volume, all have operated without incident for the past several years. Using Arcview Geographic Information Systems software (Rock Ware Inc., Golden, CO, U.S.A.), we determined the distance in miles between respondents' residence and the nearest NEP. We dichotomized all respondents as living "near" or "far" from NEP, with respondents living closer to NEP than the median distance for all respondents being classified as "near" and those living further than the median distance from NEP as "far." We used the dichotomized distance variable for the purposes of two-tailed $\chi^{2}$ tests and distance as a continuous variable in miles for the purposes of regression models, which adjusted for relevant covariates.

\section{Violence in Neighborhood}

We asked respondents if there had been "a fight in which a weapon was used" or "a robbery or mugging" in their neighborhood in the 
preceding 6 months. We also asked respondents if anyone had "ever used violence such as in a mugging, fight, or sexual assault against you or any member of your household" or if they had ever been "afraid of someone because that person was using illicit drugs," "physically hurt by someone who uses illicit drugs," or "robbed by someone who uses illicit drugs." All responses were coded as dichotomous variables ("yes/no") for the purposes of these analyses. We also used 1999 data from the New York City Police Department (NYPD) on total felony rates (per 100,000 population), felonies involving persons, and felonies involving property to validate respondents' responses about violence witnessed and experienced in their neighborhoods.

\section{Perceptions of Drug Use and Drug Users}

We elicited respondents' level of agreement with the statement "People who use illicit drugs are dangerous," rating responses on a four-point scale ranging from "strongly disagree" to "strongly agree." Responses were coded as dichotomous variables $(0=$ strongly disagree or disagree; 1 = agree or strongly agree) for these analyses. We also asked questions regarding respondents' approval or disapproval of drug use. We asked, "How do you feel about adults trying [drug] once or twice?" The question was asked twice, once for marijuana and once for cocaine. Responses were coded as a dichotomous variable $(0=$ neither approve nor disapprove or somewhat disapprove; $1=$ strongly disapprove) for these analyses.

\section{Statistical Analysis}

We compared summary descriptive statistics of our sample with Bureau of the Census data. Demographic characteristics for Harlem were obtained by aggregating census tracts for Harlem using Geographic Information Systems software and Bureau of the Census Tiger Data (29). We carried out two-tailed $\chi^{2}$ tests to examine differences in responses to questions between respondents who lived near to or far from NEPs. We used the Pearson correlation coefficient to compare census-tract level aggregate reports of violence from respondents in our study with official NYPD felony reports in these tracts. We used logistic regression (30) to measure the association between correlates of interest and distance from the nearest NEP while adjusting for baseline demographic variables.

We assessed the relations between violence and distance from the nearest NEP through multivariable logistic regression. In separate models we determined the association between respondents' 1) reporting a fight, 2) reporting a robbery, 3) experiencing violence, 4) being afraid of drug users, 5) having been physically hurt by drug users, and 6) and having been robbed by a drug user with distance from the nearest NEP. Measures of violence experienced were modeled as dependent variables, and distance from the nearest NEP was modeled as an independent variable in all models. All models were adjusted for respondents' age, race, sex, and income. We also used multivariable logistic regression to determine the association between respondents' 1 ) belief that drug users are dangerous and 2) approval of drug use with distance from the nearest NEP. The measures of respondents' attitudes were modeled as dependent variables, and distance from the nearest NEP was modeled as an independent variable in these models. All models were adjusted for respondents' age, race, sex, and income. All statistical analyses were carried out using SAS version 6.12 (SAS Institute, Cary, NC, U.S.A.) and SUDAAN (Research Triangle Park, NC, U.S.A.) software to account for the sample weighting.

\section{RESULTS}

\section{Sample Characteristics and Comparison With the Census}

The average number of calls required to complete an interview was 3.1 , with a range of 1 to 11 calls to reach respondents. The overall effective completion rate was $65 \%$. Respondents were geographically well distributed throughout Harlem, suggesting that our sampling technique was successful in obtaining a representative set of respondents throughout the neighborhood. The mean distance of respondents' residence from the nearest NEP was 0.84 miles $(\mathrm{SD}=0.51)$; the median distance was 0.72 miles.

Among 220 eligible respondents, 55.3\% were female, $31.7 \%$ had less than a high school education, and $74.1 \%$ reported a yearly income of less than or equal to $\$ 30,000$. Our sample was primarily African American (50.1\%) and Latino (39.0\%). A comparison between our sample sociodemographic characteristics and projections from the 1990 census for Harlem obtained from the STF3A summary files (31) is shown in Table 1. Our demographics are comparable to Bureau of the Census demographics (see Table 1).

\section{Violence and Attitudes Toward Drug Use by Proximity to Needle Exchange Program}

Among all respondents, $38.8 \%$ reported that a fight had occurred in their neighborhood during the past 6 months, and $43.7 \%$ reported a robbery or mugging in their neighborhood (Table 2). There was no significant difference between respondents who lived near to or far from NEPs ( $p>.50$ for both questions). Respondents' reports of violence witnessed, including reports of fights, robbery, and total violence, approximated census-tract level reports of felonies reported in 1999 by the NYPD $(r=0.27-0.67$; data not shown); that is, respondents in our study living in census tracts with higher felony rates also reported higher violence than respondents living in tracts with lower felony rates.

Personal experiences of violence were lower than reports of violence in neighborhoods; $9.7 \%$ of respondents reported ever having experienced violence in their neighborhood, $34.1 \%$ reported having been afraid of someone because that person was using illicit drugs, $9.1 \%$ reported having been physically hurt by someone using drugs, and $17.4 \%$ reported having been robbed by someone using drugs. The only significant difference in $\chi^{2}$ testing of the association between living near to or far from an NEP and each of these questions was for persons 
TABLE 1. Comparison of selected sample characteristics with 1990 Bureau of the Census data for Harlem, New York City, 2000

\begin{tabular}{|c|c|c|c|c|}
\hline \multirow[b]{2}{*}{ Variable } & \multicolumn{3}{|c|}{$\begin{array}{l}\text { Harlem Social Environmental Study } \\
\qquad(n=220)\end{array}$} & \multirow[b]{2}{*}{$\begin{array}{c}\text { Bureau of the } \\
\text { Census data }(\%)\end{array}$} \\
\hline & $\begin{array}{l}\text { Unweighted } \\
n^{a}\end{array}$ & $\begin{array}{l}\text { Unweighted } \\
(\%)\end{array}$ & $\begin{array}{l}\text { Weighted } \\
\quad(\%)\end{array}$ & \\
\hline \multicolumn{5}{|l|}{ Sex } \\
\hline Male & 99 & 45.0 & 44.7 & 45.3 \\
\hline Female & 121 & 55.0 & 55.3 & 54.7 \\
\hline \multicolumn{5}{|l|}{ Age } \\
\hline 18-34 years & 77 & 35.0 & 35.1 & 40.9 \\
\hline $35-54$ years & 81 & 36.8 & 30.8 & 31.2 \\
\hline $55-64$ years & 24 & 10.9 & 17.6 & 11.3 \\
\hline$\geq 65$ years & 38 & 17.3 & 16.5 & 16.7 \\
\hline \multicolumn{5}{|l|}{ Race } \\
\hline African American & 110 & 50.0 & 50.1 & 54.4 \\
\hline Latino & 86 & 39.1 & 39.0 & 33.0 \\
\hline Other & 24 & 10.9 & 10.1 & 12.6 \\
\hline \multicolumn{5}{|l|}{ Education } \\
\hline$<$ High school & 69 & 31.7 & 31.5 & 38.5 \\
\hline$\geq$ High school, $<4$ years of college & 100 & 47.9 & 46.1 & 36.0 \\
\hline$\geq 4$ years of college & 49 & 22.5 & 22.2 & 14.9 \\
\hline \multicolumn{5}{|l|}{ Income } \\
\hline$\leq \$ 30,000$ per year & 163 & 74.1 & 74.1 & 77.4 \\
\hline$>\$ 30,000$ per year & 57 & 25.9 & 25.9 & 22.6 \\
\hline
\end{tabular}

${ }^{a}$ Numbers may not add up to 220 because of missing values.

TABLE 2. Violence reported and attitudes toward drug use in overall sample and by proximity to needle exchange program in Harlem, New York City, 2000

\begin{tabular}{lcccc}
\hline \multicolumn{1}{c}{$\begin{array}{c}\text { Percentage of respondents } \\
\text { who answer }\end{array}$} & $\begin{array}{c}\text { Overall sample }^{b} \\
\text { (weighted, } \\
n=215.2)\end{array}$ & $\begin{array}{c}\text { Live near to NEP }^{b} \text { (weighted, } \\
n=104.8)\end{array}$ & $\begin{array}{c}\text { Live far from NEP } \\
\text { (weighted, } \\
n=110.3)\end{array}$ & $\chi^{2} p$ value $^{c}$ \\
\hline $\begin{array}{l}\text { A fight in which a weapon was } \\
\text { used occurred in their } \\
\text { neighborhood in the last 6 } \\
\text { months }\end{array}$ & 38.8 & 39.9 & 37.8 & 0.77 \\
$\begin{array}{l}\text { A robbery or mugging occurred in } \\
\text { their neighborhood in the last 6 } \\
\text { months }\end{array}$ & 43.7 & 43.2 & 44.1 & 0.91 \\
$\begin{array}{l}\text { Have ever experienced violence in } \\
\text { their neighborhood }\end{array}$ & 9.7 & 11.8 & 7.7 & 0.32 \\
$\begin{array}{l}\text { Have ever been afraid of someone } \\
\text { because that person was using } \\
\text { illicit drugs }\end{array}$ & 34.1 & 36.3 & 31.9 & 0.51 \\
$\begin{array}{l}\text { Have ever been physically hurt by } \\
\text { someone who uses illicit drugs }\end{array}$ & 9.1 & 13.5 & 4.9 & 0.03 \\
$\begin{array}{l}\text { Have ever been robbed by someone } \\
\text { who uses illicit drugs }\end{array}$ & 17.4 & 18.9 & 16.0 & 0.58 \\
$\begin{array}{l}\text { People who use illicit drugs are } \\
\text { dangerous }\end{array}$ & 72.0 & 70.5 & 73.3 & 0.66 \\
$\begin{array}{l}\text { Strongly disapprove of adults trying } \\
\text { marijuana }\end{array}$ & 55.6 & 55.7 & 55.5 & 0.98 \\
$\begin{array}{l}\text { Strongly disapprove of adults trying } \\
\text { cocaine }\end{array}$ & 73.9 & 70.6 & 77.0 & 0.30 \\
\hline
\end{tabular}

${ }^{a}$ Questions as described in detail in Methods section; percentage of respondents who answer "yes" to each question given in Table 2.

$b$ "Near" classified as closer to NEP than median distance of respondents from NEP (0.72 miles); "far" classified as equal to or further from NEP than median distance to NEP (needle exchange program).

${ }^{c}$ Two-tailed $\chi^{2} p$ value with $d f=1$; test of no association between proximity to NEP and each question. 
reporting ever having been physically hurt by someone using drugs. Of the respondents who lived near NEP, $13.5 \%$ answered "yes" to this question, and $4.9 \%$ of respondents living far from an NEP answered "yes" $(p=.03)$. There was no significant difference between attitudes toward drug use among respondents who lived near to or far from a NEP.

\section{Adjusted Relation Between Violence and Proximity to Needle Exchange Program}

In separate logistic models adjusted for age, race, sex, and income, there were no significant associations between violence experienced (modeled as dependent variable) and distance from the nearest NEP (measured as a continuous variable in miles and modeled as an independent variable) at the $\alpha=0.05$ level of significance (Table 3). There was no significant association between reporting a fight $(\mathrm{OR}=1.05, p=.89)$ or robbery $(\mathrm{OR}=1.13, p=.70)$ in the neighborhood in the previous 6 months and distance from the nearest NEP. There was also no significant association between ever having experienced violence $(\mathrm{OR}=0.71, p=.52)$ or ever having been robbed by drug users $(\mathrm{OR}=1.05, p=.91)$ and distance from the nearest NEP in adjusted models. The association between ever having been hurt by drug users and distance from the nearest NEP (OR $=0.35$, $p=.07$ ) was near significant but not consistent with the direction or magnitude of associations between violence reported and proximity to the nearest NEP observed in other adjusted models (see Table 3; models I and II). There was no appreciable change in the associations described when distance was modeled as a categoric predictor in the same adjusted models (data not shown).

\section{Adjusted Relation Between Attitudes Toward Drug Use and Proximity to Needle Exchange Program}

In separate age-, race-, sex-, and income-adjusted multivariable logistic models, there was no significant association between distance from the nearest NEP (as an independent variable) and dependent variables, including respondents' reporting that drug users are dangerous $(\mathrm{OR}=1.34, p=.42)$, that they strongly disapprove of adults trying marijuana ( $\mathrm{OR}=0.99, p=.97)$, or that they strongly disapprove of adults trying cocaine $(\mathrm{OR}=1.39, p=.36)$ (see Table 3$)$. There was no appreciable difference in results when distance was modeled as a categoric variable (data not shown).

\section{DISCUSSION}

There was no consistent association between proximity to NEPs and violence experienced or witnessed (in-

TABLE 3. Multiple logistic regression models for the adjusted associations between violence reported and attitudes toward drug use with distance from needle exchange program in Harlem, New York City, 2000

\begin{tabular}{|c|c|c|c|c|}
\hline Model & Dependent variables ${ }^{a}$ & $\begin{array}{l}\text { Adjusted odds } \\
\text { ratio }^{b}\end{array}$ & $\begin{array}{l}95 \% \text { confidence } \\
\text { interval }\end{array}$ & $p$ value \\
\hline Model I & $\begin{array}{l}\text { A fight in which a weapon was } \\
\text { used occurred in their } \\
\text { neighborhood in the last } 6 \\
\text { months }\end{array}$ & 1.05 & $0.53,2.07$ & 0.89 \\
\hline Model II & $\begin{array}{l}\text { A robbery or mugging occurred in } \\
\text { their neighborhood in the last } 6 \\
\text { months }\end{array}$ & 1.13 & $0.60,2.13$ & 0.71 \\
\hline Model III & $\begin{array}{l}\text { Have ever experienced violence in } \\
\text { their neighborhood }\end{array}$ & 0.72 & $0.26,2.01$ & 0.52 \\
\hline Model IV & $\begin{array}{l}\text { Have ever been afraid of someone } \\
\text { because that person was using } \\
\text { illicit drugs }\end{array}$ & 1.11 & $0.59,2.07$ & 0.75 \\
\hline Model V & $\begin{array}{l}\text { Have ever been physically hurt by } \\
\text { someone who uses illicit drugs }\end{array}$ & 0.35 & $0.11,1.08$ & 0.07 \\
\hline Model VI & $\begin{array}{l}\text { Have ever been robbed by someone } \\
\text { who uses illicit drugs }\end{array}$ & 1.05 & $0.49,2.23$ & 0.91 \\
\hline Model VII & $\begin{array}{l}\text { People who use illicit drugs are } \\
\text { dangerous }\end{array}$ & 1.34 & $0.66,2.71$ & 0.42 \\
\hline Model VIII & $\begin{array}{l}\text { Strongly disapprove of adults trying } \\
\text { marijuana }\end{array}$ & 0.99 & $0.52,1.87$ & 0.97 \\
\hline Model IX & $\begin{array}{l}\text { Strongly disapprove of adults trying } \\
\text { cocaine }\end{array}$ & 1.39 & $0.68,2.81$ & 0.36 \\
\hline
\end{tabular}

${ }^{a}$ All variables modeled as dependent variables in separate logistic regression models; all models adjusted for age, race, sex, and income of respondents

$b$ Odds ratio for the association between increase in 1 mile distance from needle exchange program and likelihood of answering "Yes" to dependent variable questions. 
cluding fights or robberies) by residents of Harlem in our study. Our study did not find an association between residents of Harlem ever experiencing violence and their living close to a NEP, nor did we observe an association between recent violence in the neighborhood and living close to a NEP. These results complement other recent research that found no increase in crime in a neighborhood after the introduction of a NEP (23). By asking respondents directly about violence in their neighborhood, we assessed associations that might exist between NEPs and violence that might not be detected through analyses of reported crimes or arrests. The absence of any association between respondent-reported violence and proximity to NEPs in our study adds to the evidence that NEPs do not have adverse consequences for the surrounding neighborhoods.

We also found that the attitudes of respondents toward drug users were not associated with how close they lived to a NEP. Two recent studies have assessed the effect of NEPs on adolescents' attitudes $(25,32)$. This other research suggests that most adolescents are unaware of NEPs in their neighborhoods and that NEPs are unlikely to be associated with drug use decisions. Our study showed that living close to a NEP did not affect adult respondents' attitudes toward drug use or drug users in general. These results, taken as a whole, suggest that NEPs do not substantially shape attitudes and perceptions of persons who live close by and might thus come in daily contact with drug users.

There were a number of limitations to our study that must be considered. First, our study results are consistent with the null hypotheses; as such, they do not definitively demonstrate the absence of an association between proximity to NEPs and violence. In addition, our data excluded persons without a telephone. Current population surveys suggest that up to $14 \%$ of Puerto Rican households nationally may have no telephone and that $18 \%$ of Harlem residents are Puerto Rican (31). Although households without a telephone were underrepresented in our sample, a demographic breakdown of our respondents suggests that, if anything, we oversampled Latinos (39\% in our sample compared with 33\% in Bureau of the Census demographics). We also note that persons without a telephone may be living in poorer areas in Harlem, potentially having closer daily contact and different experiences with IDUs than the persons we surveyed.

We were interested in the association between persons living close to NEPs and violence experienced in their neighborhoods. We did not ask about respondents' work location or whether they came in contact with IDUs on a regular basis anywhere else. Contact with IDUs at work or elsewhere might be associated with respondents' choice of residence and with their experiences of violence, potentially introducing an unmeasured confounder in our study. Nondifferential misclassification bias could also have affected our results if respondents reported violence they knew of in different neighborhoods. We note that we did not impose a definition of "neighborhood" on respondents, allowing study participants to interpret their neighborhood as representing any area around their residence that was appropriate for them. These results are then applicable to any definition of neighborhood that was appropriate for individual respondents in our study.

We were also limited by our measurement of proximity to NEPs. We measured distance "as the crow flies" from the respondents' residence to the nearest NEP. Geographic distance in urban areas may be an imperfect proxy for proximity to NEPs because of factors such as geographic barriers, traffic patterns, or public transport. We also assumed that all NEPs in Harlem have an equal impact on their neighborhood. It is possible that NEPs with different characteristics (e.g., street outreach) can have different effects on their neighborhoods.

This cross-sectional study allows no conclusions about causality in any of the associations studied. We asked respondents about violence in their neighborhood during the previous 6 months as well as about their lifetime personal experience of violence. Although these variables were not associated with distance from NEPs, we would be cautious about concluding that NEPs in neighborhoods do not cause an increase in violence.

Our survey asked respondents whether they had ever been harmed or robbed by someone who uses illicit drugs. We note that we did not ask respondents who were harmed or robbed how they were able to verify that the perpetrator was a substance user. It is possible that this introduces misclassification bias in respondents' assessments of personal harm or robbery by drug users.

In conclusion, our study showed that there was no consistent association between persons living close to NEPs and violence experienced in Harlem neighborhoods. There was also no association between respondents' attitudes toward drug users and proximity to NEPs. In conjunction with other studies that have shown the absence of an association between NEPs and crime, discarded needles, and adolescent attitudes, our data suggest that NEPs do not affect their neighbors' experiences. Public health officials and health educators can use the findings from this and similar studies to reassure community residents and public officials that the presence of a NEP does not seem to threaten public safety in the surrounding neighborhood. Because such fears have contributed to opposition to the establishment or expansion 
of NEPs and other harm reduction programs, this reassurance may help to create more support for public health measures that have been shown to assist in the prevention of HIV transmission.

Acknowledgments: This work was partly funded by a Centers for Disease Control and Prevention Urban Research Centers grant U48/CCU209663-07.

\section{REFERENCES}

1. Centers for Disease Control and Prevention. Available at: http://www.cdc.gov/hiv/stats.htm. Accessed November 28, 2000.

2. AIDS New York City. AIDS surveillance update. First quarter 1998. New York: New York City Department of Health, Office of AIDS Surveillance, 1998.

3. Vlahov D, Junge B. The role of needle exchange programs in HIV prevention. Public Health Rep 1998;113(Suppl 1):75-80.

4. Des Jarlais DC, Marmor M, Paone D, et al. HIV incidence among injecting drug users in New York City syringe-exchange programmes. Lancet 1996;348:987-91.

5. Hagan H, Des Jarlais DC, Friedman SR, et al. Reduced risk of hepatitis $\mathrm{B}$ and hepatitis $\mathrm{C}$ among injection drug users in the Tacoma syringe exchange program. Am J Public Health 1995;85: 1531-7.

6. Strathdee SA, van Ameijdan EJ, Mesquita F, et al. Can HIV epidemics among injection drug users be prevented? AIDS 1998;12(Suppl A):S71-9.

7. Vlahov D, Junge B, Brookmeyer R, et al. Reductions in high-risk drug use behaviors among participants in the Baltimore needle exchange program. J Acquir Immune Defic Syndr Hum Retrovirol 1997;16:400-6.

8. Guydish J, Bucardo J, Clark G, Benheim S. Evaluating needle exchange: a description of client characteristics, health status, program utilization, and HIV risk behavior. Subst Use Misuse 1998; 33:1173-96.

9. Doherty MC, Junge B, Rathouz P, et al. The effect of a needle exchange program on numbers of discarded needles: a 2-year follow-up. Am J Public Health 2000;90:936-9.

10. Heimer R. Can syringe exchange serve as a conduit to substance abuse treatment? J Subst Abuse Treat 1998;15:183-91.

11. Brooner R, Kidorf M, King V, et al. Drug abuse treatment success among needle exchange participants. Public Health Rep 1998;113(Suppl 1):129-39.

12. Strathdee S, Celentano D, Shah N, et al. Needle-exchange attendance and health care utilization promote entry into detoxification. J Urban Health 1999;76:448-60.

13. Normand N, Vlahov D, Moses LE. Preventing HIV transmission: the role of sterile needles and bleach. Washington, DC: National Academy Press, 1995.

14. Lee B. Congresswoman Lee pledges support to lift ban on federal funds for needle exchange programs. [press release]. Available at: http://www.cacho.ww.ban+on+needle+exchange+programs. Accessed April 24, 1998.

15. National Research Council and Institute of Medicine. Needle ex- change programs reduce HIV transmission among people who inject illegal drugs. Office of News and Public Information, Washington, DC: 1998.

16. Goodlatte R, Armey R, Tiahrt T. Send the right message to our children: just say NO to free needles for drug addicts [letter] Washington, DC: Congress of the United States of America, 1999.

17. Reid RJ. A benefit-cost analysis of syringe exchange programs. $J$ Health Soc Policy 2000;11:41-57.

18. Jacobs P, Calder P, Taylor M, et al. Cost effectiveness of Streetworks' needle exchange program of Edmonton. Can J Public Health. 1999;90:168-71.

19. Fuller C, Arria A, Ompad D, et al. Changing patterns in injection practices and other drug use before and after the start of NEP among adolescents and young adults who recently initiated injection drug use in the Risk Evaluation and Community Health Study (REACH II) [poster presentation]. Presented at the XII World AIDS Conference, Geneva, June 28-July 3, 1998.

20. Hart GJ, Carvell AL, Woodward N, et al. Evaluation of needle exchange in central London: behaviour change and anti-HIV status over one year. AIDS 1989;3:261-5.

21. Hartgers C, van Ameijden EJ, van den Hoek JA, Coutinho RA. Needle sharing and participation in the Amsterdam Syringe Exchange program among HIV-seronegative injecting drug users. Public Health Rep 1992;107:675-81.

22. Watters JK, Estilo MJ, Clark GL, Lorvick J. Syringe and needle exchange as HIV/AIDS prevention for injection drug users. JAMA 1994;271:115-20.

23. Marx MA, Crape B, Brookmeyer R, et al. Trends in crime associated with the introduction of a needle exchange program. Am J Public Health 2000;90:1933-6.

24. Inciardi J. Heroin use and street crime. Crime Delinquency. 1989; 25:335-46.

25. Marx MA, Beilenson $\mathrm{P}$, Brahmbhatt $\mathrm{H}$, et al. Attitudes of adolescents about illegal drug use and needle exchange programs. AIDS Behav (in press).

26. Fullilove RE, Fullilove MT, Northridge ME, et al. Risk factors for excess mortality in Harlem: Findings from the Harlem Household Survey. Am J Prev Med 1999;16(Suppl 3):S22-8.

27. Hartge P, Brinton LA, Rosenthal JF, et al. Random digit dialing in selecting a population-based control group. Am J Epidemiol 1984; 120:825-33.

28. Kish L. A procedure for objective respondent selection within the household. J Am Statistical Assoc 1949;44:380-7.

29. Bureau of the Census. Washington, DC: US Department of Commerce. 1995. Available at: http://www. census.gov/geo/www/tiger. Accessed October 30, 2000.

30. Kleinbaum DG, Kupper LL, Muller KE, Nizam A. Applied regression analysis and other multivariable methods. Pacific Grove, CA Brooks/Cole Publishing Company, 1998.

31. Bureau of the Census. Census summary tape, file 3A (STF3A). Washington, DC: US Department of Commerce. 1990. Available at: http://www.census.gov/ftp /pub/population/ www/estimates/ co_crh.html. Accessed October 30, 2000.

32. Friedman SR, Jose B, Flom PL, et al. The message not heard: myth and reality in discussions about syringe exchange. AIDS 1999;3 738-9. 